\title{
Computational Techniques for Novel Design of Long-Span Bridges Considering Aeroelastic Phenomena
}

Miguel Cid Montoya, Ph.D. ${ }^{1}$; Félix Nieto, M.ASCE ${ }^{2}$; Santiago Hernández, F.ASCE ${ }^{3}$; Ahsan Kareem, M.ASCE ${ }^{4}$; and Fei Ding ${ }^{5}$

${ }^{1}$ School of Civil Engineering, Univ. of La Coruña, La Coruña, Spain; NatHaz Modeling Laboratory, Univ. of Notre Dame, Notre Dame, IN, USA. E-mail: miguel.cid.montoya@udc.es

${ }^{2}$ Ass. Prof., School of Civil Engineering, Univ. of La Coruña, La Coruña, Spain. E-mail: fnieto@udc.es

${ }^{3}$ Prof., School of Civil Engineering, Univ. of La Coruña, La Coruña, Spain. E-mail: hernandez@udc.es

${ }^{4}$ Prof., NatHaz Modeling Laboratory, Univ. of Notre Dame, Notre Dame, IN, USA. E-mail: kareem@nd.edu

${ }^{5}$ NatHaz Modeling Laboratory, Univ. of Notre Dame, Notre Dame, IN, USA. E-mail: fding@nd.edu

\begin{abstract}
Optimization techniques have demonstrated their capability to obtain economic and sustainable designs while meeting the performance and safety requirements in a number of engineering disciplines. In the bridge engineering field, the increasing main span length of superlong span bridges makes the wind-resistant design a top priority. However, it has been traditionally conducted following heuristic rules based on experimental analyses. Alternatively, the last advances in CFD and metamodeling techniques enables the development of optimization frameworks. The right conception of the aerostructural optimization problem is crucial to achieve noticeable reductions in the required amount of material and comprehensive safe designs. This paper reports the last advances in the authors' line of research that pursues the definition of a numerical methodology for the full aerostructural optimization of long-span bridges considering shape and size design variables. The capabilities of the method are presented, and the necessity of considering uncertainty in the process is discussed.
\end{abstract}

\section{INTRODUCTION}

The last two decades can be considered as a golden period for the design and construction of long-span bridges. Suspension bridges with main span between $1500 \mathrm{~m}$ to $2000 \mathrm{~m}$ have been built in many places, such as the Akashi Bridge, in Japan, the Great Belt Bridge, in Denmark, the Xihoumen Bridge, in China, the Yi Sun-sin Bridge, in South Korea, or the Osman Gazi Bridge, in Turkey. Furthermore, more advanced typologies such as suspension bridges with two main spans are nowadays more commonly adopted as efficient solutions. This is the case of the Taizhou and Ma'anshan bridges, in China, and the Chacao Bridge, in Chile.

The case of cable-stayed bridges is quite similar. Since 1999, many bridges have been built with main span between almost $900 \mathrm{~m}$ to $1100 \mathrm{~m}$, such as the Tatara Bridge, in Japan, the Stonecutters, Sutong and Edong bridges, in China, and Russky Bridge, in Russia. Again, new typologies consisting in multi-span cable-stayed bridge has been conceived, as it is the case of the Rio-Antirrio Bridge in Greece and the Queensferry Crossing over the Firth of Forth, in UK, which has a crossing cable system aimed to increase the overall stiffness of the structure.

These kind of bridges need to have an efficient performance under wind-induced phenomena. 
In the past, the studies to find out their behavior were carried out through wind tunnel tests of reduced-scale models of the full bridge. The increasing length of these constructions forced to set up wind tunnels of larger dimensions, being the best example the one at Tsukuba, Japan, which had a test chamber about $50 \mathrm{~m}$ wide. Fortunately, an alternative to this type of experiments is sectional model testing. It consists of testing a reduced model of a segment of the bridge deck with the objective of obtaining the aeroelastic parameters, such as flutter derivatives and admittance functions, and then carry out computational analyses to find out the aeroelastic response of the whole bridge, such as flutter velocity or buffeting-induced accelerations. This trend to move from purely experimental techniques to computational approaches can be further pursued by taking advantage of the current capabilities of numerical techniques, such as Computational Fluid Dynamic CFD simulations and surrogate models, and combine them with optimization algorithms. This approach has a great potential, especially in the case of novel bridge typologies where no previous experiences are at designer's disposal.

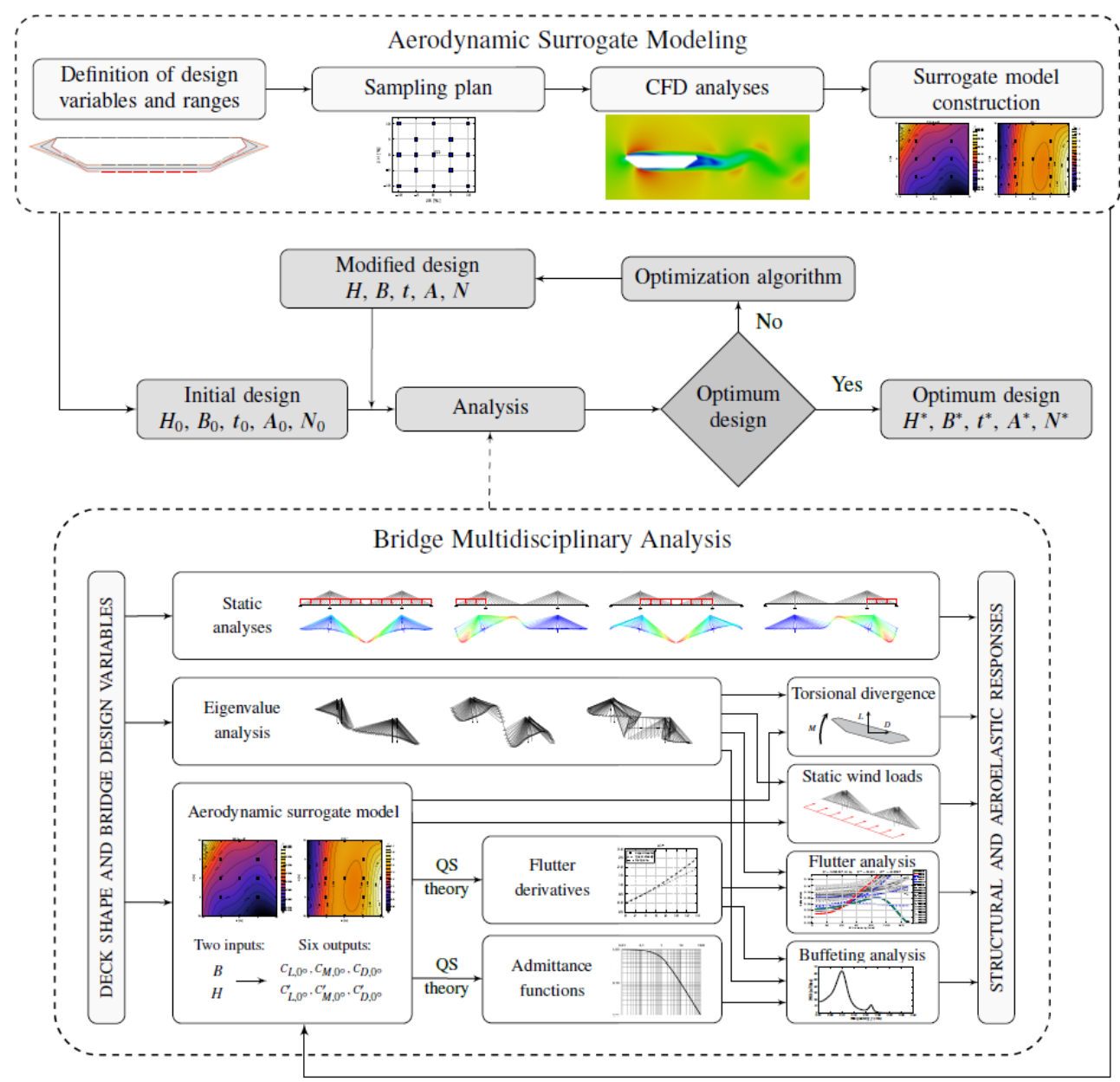

Figure 1. Flowchart of the methodology for the aerostructural shape optimization.

The application of optimization algorithms to the structural design of cable-supported bridges dates back to the 90's, with the first applications by Simões and Negrão, 1994. In that work, and later contributions, the bridge was optimized considering structural responses, such as kinematic and stress levels of structural elements under the actions of dead and live loads, and eventually under the seismic effects (Ferreira and Simões, 2011). The first appearance of the aeroelastic 
performance in a bridge optimization problem was in the work by Nieto et al. 2009, where the design of the Messina Bridge project was optimized considering the critical flutter velocity. Later, in Kusano et al. 2014, the approach was improved by considering the inherent uncertainties present in the determination of the flutter derivatives.
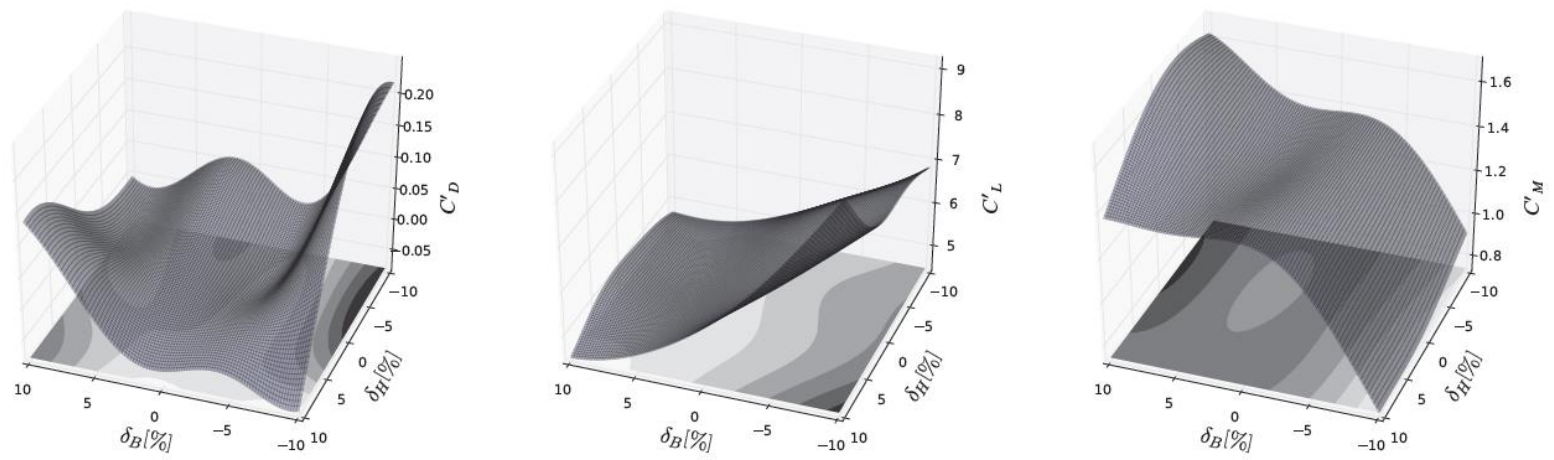

Figure 2. Response surfaces of the ASM for the slopes of the force coefficients. Data taken from Cid Montoya et al. (2018a).

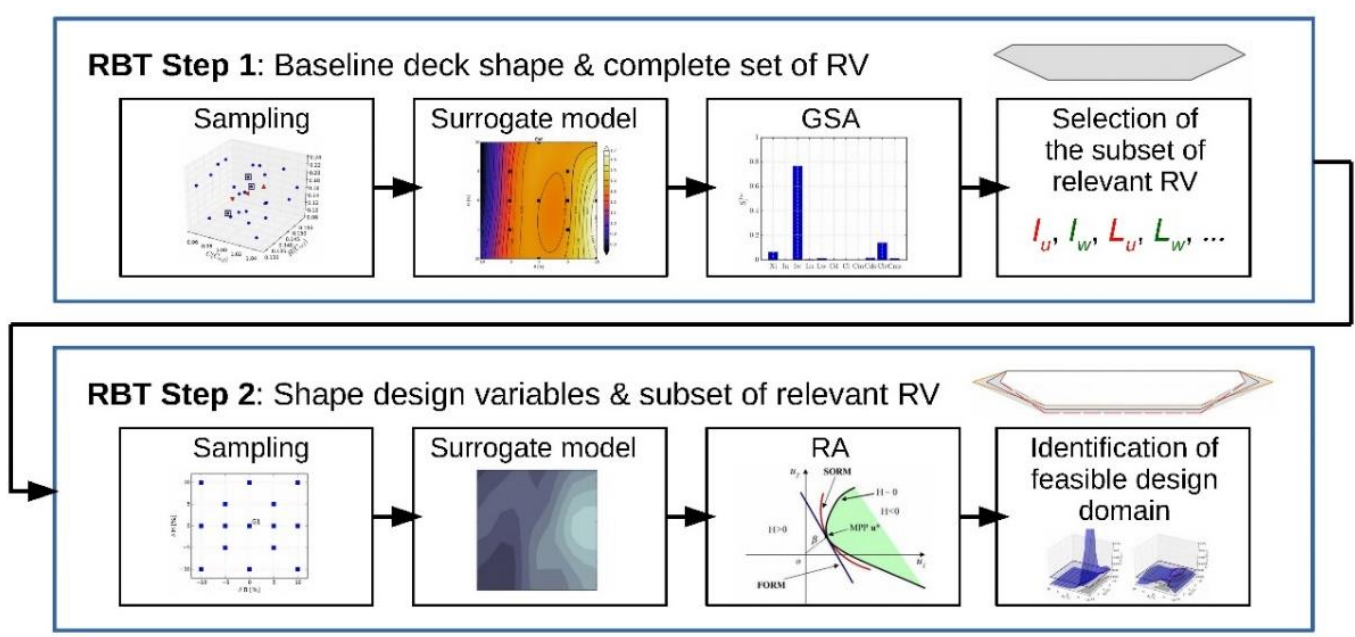

Figure 3: Methodology for carrying out reliability based tailoring of a deck geometry.

However, in the aforementioned contributions the key design parameter for both structural an aeroelastic design of long-span bridges remains unmodified: the deck cross-section geometry. This was included in the authors' previous work Cid Montoya et al., 2018a, where a methodology combining CFD simulations, Design of Experiments (DoE) methods and surrogate models, was developed to generate data that can substitute the information provided by the sectional tests carried out in wind tunnels. This methodology was extended in Cid Montoya et al., 2018b, where a numerical framework was developed for the aerostructural shape optimization of long-span bridges. In this last work, a cable-stayed bridge with a mono-box deck cross section was optimized considering as design variables (DV) the shape and size of the deck and the stay cross-section areas of the cable supporting system, and as design constraints a number of structural constraints and the flutter velocity. The results obtained demonstrated that the deck cross-section geometry plays an important role in the bridge design, given that it controls the deck aerodynamics and mechanical properties, particularly the mass moment of inertia as well as vertical and torsional stiffness (see Cid Montoya et al., 2019a, for further 
insights). In recent contributions (Cid Montoya et al. 2019b), this methodology was extended by including more aeroelastic phenomena in the problem as design constraints, such as aerostatic stability, and deck accelerations and displacements due to buffeting. Furthermore, it is planned in the near future to improve the formulation by including vortex-induced vibrations (VIV), leading to a methodology that considers all aeroelastic phenomena that can challenge the bridge performance and safety. In this paper, these methodologies are presented and an application example is studied.

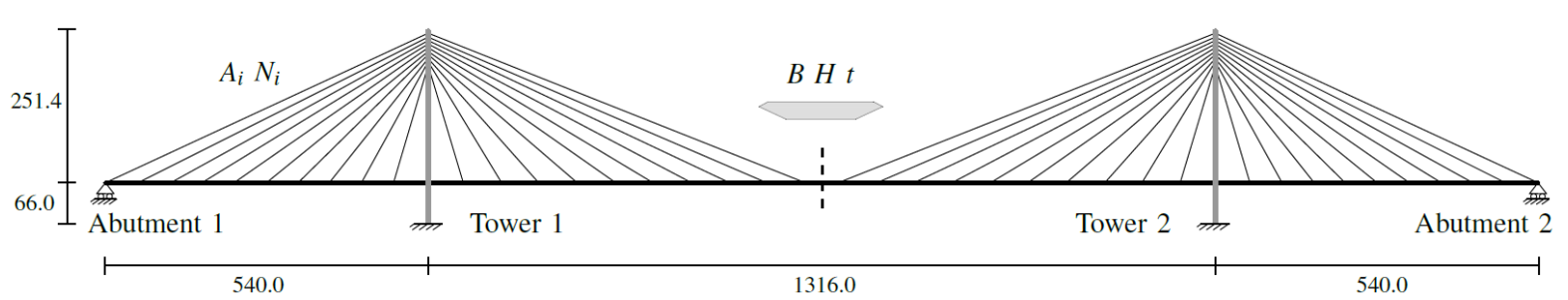

Figure 4: Layout of the bridge model considered to carry out the aerostructural optimization.

Another important aspect in the wind-resistant design and optimization of long-span bridges is the consideration of the uncertainties that may affect the problem, particularly to the wind load modeling, the aerodynamic and aeroelastic characterization, and the structural modeling. This paper also analyzes how this aspects affect the design of long-span bridges and suggest some guidelines for the development of efficient reliability-based design optimization frameworks.

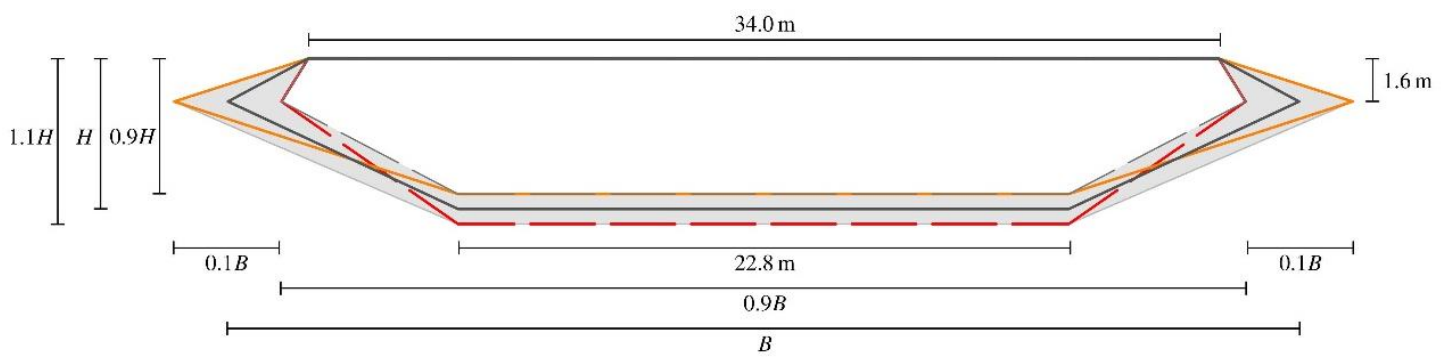

Figure 5: Definition of the shape variations allowed to the deck cross-section geometry.

\section{NUMERICAL METHODOLOGY FOR THE AEROSTRUCTURAL SHAPE OPTIMIZATION OF LONG-SPAN BRIDGES}

The methodology developed to carry out the aerostructural shape and size optimization of long-span bridges considering deck shape variations is sketched in Figure 1. The key step in this process is the construction of an Aerodynamic Surrogate Model (ASM) before conducting the aerostructural optimization. This aerodynamic emulator provides to force coefficients and their slopes for any design candidate analyzed by the optimization algorithms, and it is built from the responses of CFD simulations. This information will be used in each evaluation proposed by the gradient-based optimization algorithm, particularly it will be required in some stages of the Bridge Multidisciplinary Analysis (BMA). The BMA is a numerical process that assess all the responses of the bridge by a number of analysis. First, the kinetic and stress responses of the bridge under live and dead loads of structural nature are obtained by means of static analyses of a finite element model (FEM) of the whole bridge. Then, the dynamic responses of the bridge 
required by the aeroelastic analyses, such as natural frequencies and mode shapes, are obtained using again the FEM. The following step, which can be conducted in parallel with the previous two, consists of the evaluation of the ASM to obtain the force coefficients and their slope for the particular deck cross-section under study in the current evaluation, and the application of the quasi-steady (QS) formulation to estimate the aeroelastic parameters, which are the flutter derivatives (FD) and the admittance functions (AF). With all this information, all aeroelastic analyses can be carried out, such as flutter, buffeting and aerostatic stability.

Procedure for the estimation of the aeroelastic parameters: The time-averaged force coefficients of a deck-cross section under the action of wind can be expressed as

$$
C_{D}=\frac{D}{\frac{1}{2} \rho U^{2} B}, C_{L}=\frac{L}{\frac{1}{2} \rho U^{2} B} \text {, and } C_{M}=\frac{M}{\frac{1}{2} \rho U^{2} B^{2}},
$$

where $\rho$ is the air density, $U$ is the wind velocity, $B$ is the width of the cross-section, used as reference dimension, and $L, D$ and $M$ are the time-averaged lift and drag forces and moment per unit of length respectively. The sign convention adopted is that the positive values are nose-up for the moment, upward for the vertical force and down-wind for the drag.

The flutter derivatives (FD) were first introduced by Scanlan and Tomko (1971) to experimentally evaluate the aeroelastic forces acting on a bridge deck cross-section. The quasisteady (QS) formulation (see, for instance, Tubino 2005) provides a numerical alternative to estimate these functions as follows

$$
\begin{aligned}
& H_{1}^{*}=-\frac{C_{L}^{\prime}+C_{D}}{K}, \quad H_{2}^{*}=\frac{C_{L}^{\prime}+C_{D}}{K} \mu_{H}, \quad H_{3}^{*}=-\frac{C_{L}^{\prime}}{K^{2}}, \quad H_{5}^{*}=-\frac{2 C_{L}}{K} \\
& A_{1}^{*}=\frac{C_{M}^{\prime}}{K}, \quad A_{2}^{*}=\frac{C_{M}^{\prime}}{K} \mu_{A}, \quad A_{3}^{*}=\frac{C_{M}^{\prime}}{K^{2}}, \quad A_{5}^{*}=\frac{C_{M}}{K} \\
& P_{1}^{*}=\frac{2 C_{D}}{K}, \quad P_{2}^{*}=\frac{C_{D}^{\prime}-C_{L}}{K} \mu_{P}, \quad P_{3}^{*}=\frac{C_{D}^{\prime}}{K^{2}}, \quad P_{5}^{*}=\frac{C_{D}^{\prime}-C_{L}}{K}
\end{aligned}
$$

where the FD are predicted based on the values of the force coefficients and slopes, that can be provided by a surrogate model. $\mu_{H}$ and $\mu_{A}$ can be obtained as (Larose and Livesey (1997)

$$
\mu_{H} \approx \frac{A_{1}^{*}}{H_{1}^{*}} \text { and } \mu_{A} \approx \frac{A_{3}^{*}}{H_{3}^{*}} \text {. }
$$

Similarly, the admittance functions can be estimated taking advance of the QS formulae as given by

$$
\begin{gathered}
\chi_{D u}^{*}=2 C_{D} A\left(f^{*}\right) \quad \chi_{L u}^{*}=2 C_{L} A\left(f^{*}\right) \quad \chi_{M u}^{*}=2 C_{M} A\left(f^{*}\right) \\
\chi_{D w}^{*}=\left(K_{D}-C_{L}\right) A\left(f^{*}\right) \quad \chi_{L w}^{*}=\left(K_{L}-C_{D}\right) A\left(f^{*}\right) \quad \chi_{M w}^{*}=K_{M} A\left(f^{*}\right)
\end{gathered}
$$

where $A\left(f^{*}\right)$ is the Davenport admittance, which will be used in this work.

Aerodynamic surrogate model (ASM): Some optimization problems that involve the recursive evaluation of time-consuming analyses, such as CFD simulations, became numerically unapproachable. Hence, alternative strategies must be explored, such as surrogate-based optimization. Surrogate modelling is a numerical technique that enables the substitution of a time-consuming implicit model, considered as truth or high-fidelity model, by an analytical approximation, known as surrogate model, emulator, or metamodel. Further insights can be found in Forrester at al. 2008, and some interesting applications in the wind engineering field are 
reported in Bernardini et al. 2015, Elshaer et al. 2017 and Ding and Kareem, 2018.

The methodology presented in this work relies on the use of surrogate models to emulate the aerodynamic response provided by CFD simulations. The particular ASM used in this work was developed and validated in the authors' previous work Cid Montoya et al. (2018a). This emulator was built from the responses of 15 designs deterministically distributed along the design domain. The outputs of the model are the force coefficients and their slopes, which required that for each of the 15 designs considered in the sampling plan two CFD simulations were carried out to obtain the force coefficients at wind angles of attack $\alpha=0^{\circ}$ and $\alpha=2^{\circ}$. The 2D Unsteady Reynolds-Averaged Navier-Stokes (URANS) was adopted for the CFD simulations, and the turbulence model used was the Menter's $k$ - $\omega$ Shear-Stress Transport (SST) (Menter and Esch (2001)). Validation studies were conducted at the Aerodynamic Wind Tunnel (TUVA) at the University of La Coruña. The response surfaces obtained with the ASM for the slopes of the force coefficients are shown in Figure 2.

Formulation of the deterministic optimization problem: The goal of the optimization problem is to minimize the volume of material of the bridge aiming to produce more efficient and sustainable designs. However, the resulting design must meet a number of design requirements of structural and aeroelastic nature, leading to the concept of aerostructural optimization. Hence, the problem is formulated as:

$$
\min F(\mathbf{x})=\min F(B, H, t, \mathbf{A}, \mathbf{N})=A_{x}(B, H, t) L_{D}+P_{s} \sum_{i=1}^{n_{s}} A_{i} L_{s, i}
$$

subject to

$$
\begin{gathered}
g_{r}^{\text {Str }}(\mathbf{x})=\frac{R_{r}}{R_{r, \max }}-1 \leq 0, \quad r=1, \ldots, n_{r} \\
g_{a}^{\text {Aero }}(\mathbf{x})=\frac{R_{a}}{R_{a, \max }}-1 \leq 0, \quad r=1, \ldots, n_{a}
\end{gathered}
$$

where $F$ is the objective function and $\mathbf{x}$ represents all DV, including the width $B$ and depth $H$ of the deck, the deck plate thickness $t$, the stay cross-section areas $\mathbf{A}$ and the stays prestressing forces $\mathbf{N}$. In the definition of $F, A_{x}$ stands for the deck cross-section area, $L_{D}$ represent the total length of the deck, $P_{s}$ stands for the number of planes of stays, which is usually $2, n_{s}$ provides the number of stays, and $L_{s, i}$ the length of each stay. Regarding the design constraints, $g$ represents normalized design constraints, which can be of structural $g_{r}^{S t r}(\mathbf{x})$ or aeroelastic $g_{a}^{\text {Aero }}(\mathbf{x})$ nature. There are $n_{r}$ structural constraints, where $R_{r}$ is the structural response and $R_{r, \max }$ is the maximum value accepted. Furthermore, the problem considers a number of $n_{a}$ aeroelastic constraints, where $R_{a}$ is the aeroelastic response of the design and $R_{a, \max }$ the threshold adopted.

\section{EXTENDED METHODOLOGY FOR THE AEROSTRUCTURAL RELIABILITY- BASED SHAPE OPTIMIZATION OF LONG-SPAN BRIDGES}

Aerolastic responses of long-span bridges are influenced by a large number of parameters with inherent probabilistic nature. This was soon noted at the early stages of the wind engineering discipline by several researchers (Davenport,1983, Kareem, 1988a and 1988b). In the last two decades, several contributions studying the uncertainty propagation and/or reliability 
analysis of long-span bridges considering flutter (Ge et al. 2000; Argentini et al. 2014; Mannini and Bartoli, 2015) or buffeting (Solari and Piccardo, 2001; Caracoglia, 2008) have been conducted. However, these techniques were not implemented into design frameworks and they were just merely applied for validate final designs. Only in the works by Kusano et al. (2014, 2018), the formulation of the reliability-based design optimization considering flutter was developed.

Table 1: Summary of structural and aeroelastic constraints considered in the aerostructural optimization problem.

\begin{tabular}{|c|c|c|c|c|c|}
\hline Type & Location & Limit constraint value & \# points & Loads & \# constr. \\
\hline \multirow{2}{*}{$\begin{array}{l}\text { Displacement } \\
\text { under } S W\end{array}$} & Deck nodes & $w_{\max }=0.05 \mathrm{~m}$ & 38 & $S W(1)$ & 38 \\
\hline & Tower top nodes & $u_{\max }=0.05 \mathrm{~m}$ & 2 & $S W(1)$ & 2 \\
\hline \multirow{3}{*}{$\begin{array}{l}\text { Displacement } \\
\text { under } L_{i}\end{array}$} & Lateral spans & $w_{\max }=540 \mathrm{~m} / 500=1.080 \mathrm{~m}$ & 18 & $L(4)$ & 72 \\
\hline & Main span & $w_{\max }=1316 \mathrm{~m} / 500=2.632 \mathrm{~m}$ & 20 & $L(4)$ & 80 \\
\hline & Tower top nodes & $u_{\max }=314.4 \mathrm{~m} / 600=0.524 \mathrm{~m}$ & 2 & $L(4)$ & 8 \\
\hline \multirow{3}{*}{$\begin{array}{l}\text { Stress under } \\
\text { SW and } L_{i}\end{array}$} & Deck top fiber & $\sigma_{\max }=200 \mathrm{MPa}$ & 88 & $L(4)$ & 352 \\
\hline & Deck bottom fiber & $\sigma_{\max }=200 \mathrm{MPa}$ & 88 & $L(4)$ & 352 \\
\hline & Stays & $\sigma_{\max }=800 \mathrm{MPa}$ & 40 & $S W \& L(5)$ & 200 \\
\hline \multirow{6}{*}{$\begin{array}{l}\text { Buffeting: RMS } \\
\text { of acc. }(U) \\
{\left[\mathrm{m} / \mathrm{s}^{2}\right]}\end{array}$} & Deck lateral acc. & $\ddot{u}_{R M S \max }=[0.005,0.04,0.15,0.3]$ & 171 & $U_{w}(4)$ & 684 \\
\hline & Deck vertical acc. & & 171 & $U_{w}(4)$ & 684 \\
\hline & Deck rotational & $\ddot{w}_{R M S, \max }=$ & 171 & $U_{w}(4)$ & 684 \\
\hline & acc. & {$[0.015,0.1,0.275,0.55]$} & & & \\
\hline & & $\ddot{Z}_{e q, R M S, \max }=$ & & & \\
\hline & & {$[0.005,0.05,0.15,0.35]$} & & & \\
\hline \multicolumn{2}{|c|}{ Total number of design constraints } & & & & 3156 \\
\hline
\end{tabular}

In the authors' previous work (Cid Montoya et al. 2019c), a numerical framework for the reliability-based tailoring (RBT) of bridge decks for buffeting response was presented. In the present work, some results are commented to evaluate the relevance of uncertainty in the buffeting responses and to analyze the viability of considering the inherent uncertainties of the problem in the optimization framework shown in the previous section. The main challenge is the large number of uncertainties to be considered in the problem. This drawback limits the applicability of surrogate models to emulate the buffeting response of the bridge, since the required number of samples in the sampling plan to explore the whole domain increases with the dimension of the problem (Forrester et al. 2008). An efficient alternative to overcome this problem is to select a subset of random variables (RV) that affect the buffeting responses the most, by taking advantage of Global Sensitivity Analyses (GSA) (Sobol', 2001) to reduce the dimension of the problem and the requirements of the sampling plan to build the surrogate. Following this idea, the two-step design framework shown in Figure 3 can be used. The first step works with the initial deck shape of the deck and seeks to reduce the dimension of the problem. A surrogate model of the buffeting response considering as inputs all the RV is built and used to conduct GSA to obtain the Sobol' indices. This information allows to select the most important $\mathrm{RV}$, and consequently to reduce the dimension of the problem. Then, in the second step, a new surrogate model of the buffeting response considering the deck shape variables and the subset of $\mathrm{RV}$ chosen in the previous step will enable to perform reliability analysis of the buffeting performance of the structure with contained computational demands. 
Table 2: Summary of the results obtained in the aerostructural optimization.

\begin{tabular}{|c|c|c|c|c|c|c|c|c|}
\hline Iter. & $F[\mathrm{~m} 3]$ & $B[\mathrm{~m}]$ & $H[\mathrm{~m}]$ & $t[\mathrm{~cm}]$ & $\begin{array}{c}\overline{\boldsymbol{A}^{\boldsymbol{B}}} \\
{[\mathrm{m} 2]}\end{array}$ & $\begin{array}{c}\overline{\boldsymbol{A}^{\boldsymbol{s}}} \\
{[\mathrm{m} 2]}\end{array}$ & $\begin{array}{l}\overline{\boldsymbol{N}} \\
{[\mathrm{MPa}]}\end{array}$ & Active aero. constr. \\
\hline 1 & 7619.20 & 40.000 & 5.600 & 2.500 & 0.5000 & 0.0500 & 500.0 & - \\
\hline 68 & 6998.57 & 40.536 & 6.160 & 2.209 & 0.5410 & 0.0409 & 456.0 & $\ddot{w}_{60}^{m}$ \\
\hline
\end{tabular}

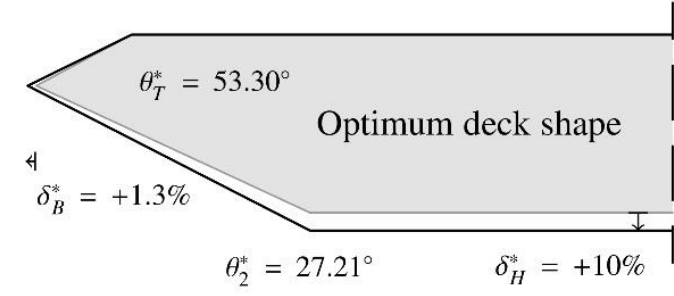

(a) Initial and optimum deck shape design.

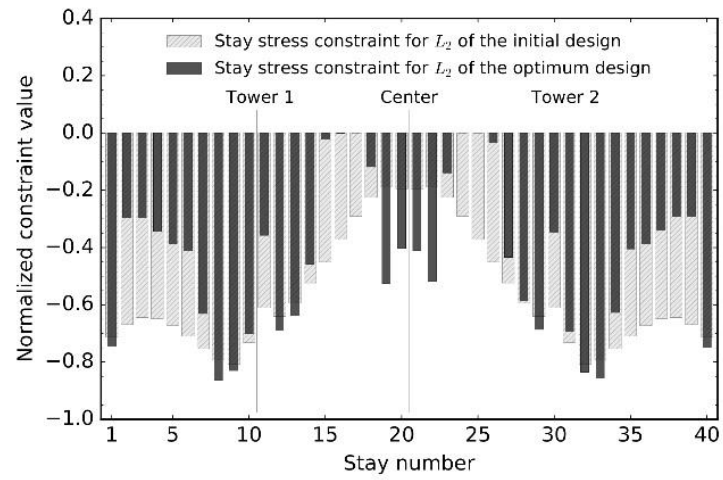

(c) Stress on the stays for load case $L_{2}$.

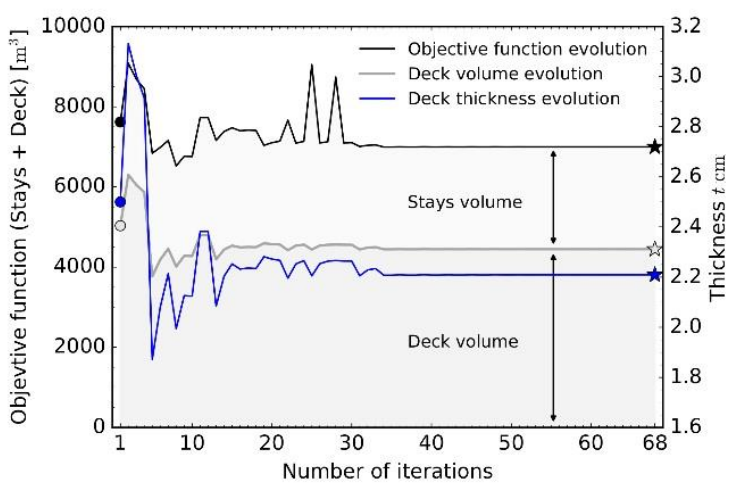

(e) Convergence of $F$ and deck volume.

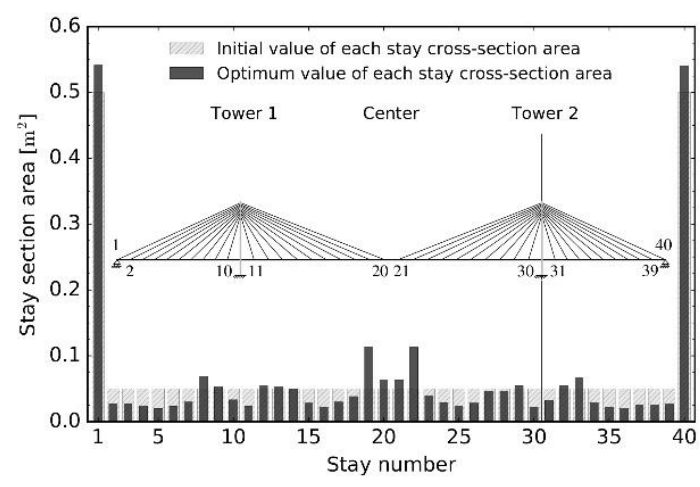

(b) Initial and optimum design of stay areas.

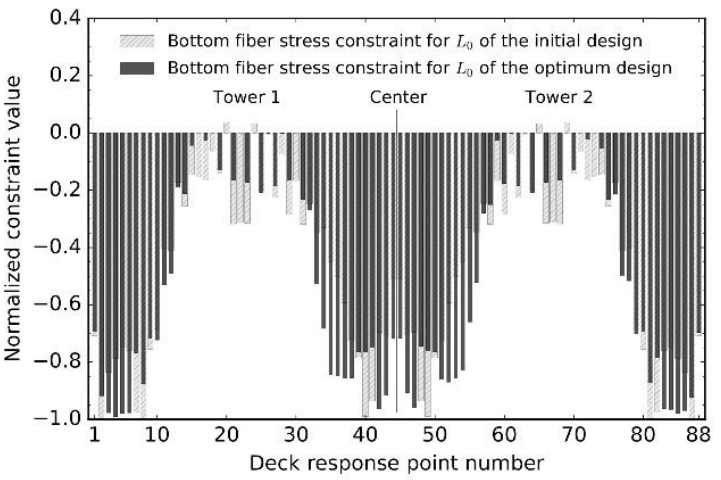

(d) Stress on the deck bottom fiber for load case $L_{0}$.

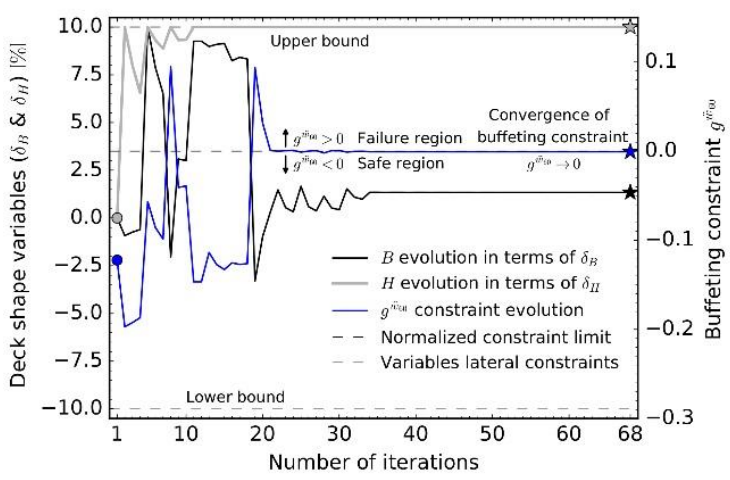

(f) Convergence of buffeting acceleration constraint.

Figure 6: Subset of results: Shape and size DV, structural constraints and convergence. 


\section{APPLICATION CASE \#1: DETERMINISTIC AEROSTRUCTURAL SHAPE OPTIMIZATION OF A LONG-SPAN CABLE-STAYED BRIDGE CONSIDERING STRUCTURAL AND BUFFETING CONSTRAINTS}

The first application case reported in this piece of research consists of an aerostructural shape optimization problem of a long-span cable-stayed bridge considering structural and buffeting constraints but without having into account uncertainties. Therefore, this is a deterministic optimization problem. The cable-stayed bridge used as application example, which is shown in Figure 4, has a main span of $1316 \mathrm{~m}$, in the order of magnitude of the longest cable-stayed bridges in the world, such as the Russky, Sutong, or Stonecutters bridges. The initial design of the cable supporting system consists of two backstays with a cross-section area of $A^{B}=0.5 \mathrm{~m}^{2}$ and 38 stays with $A^{S}=0.05 \mathrm{~m}^{2}$. The modal damping considered is $\xi=0.01$.

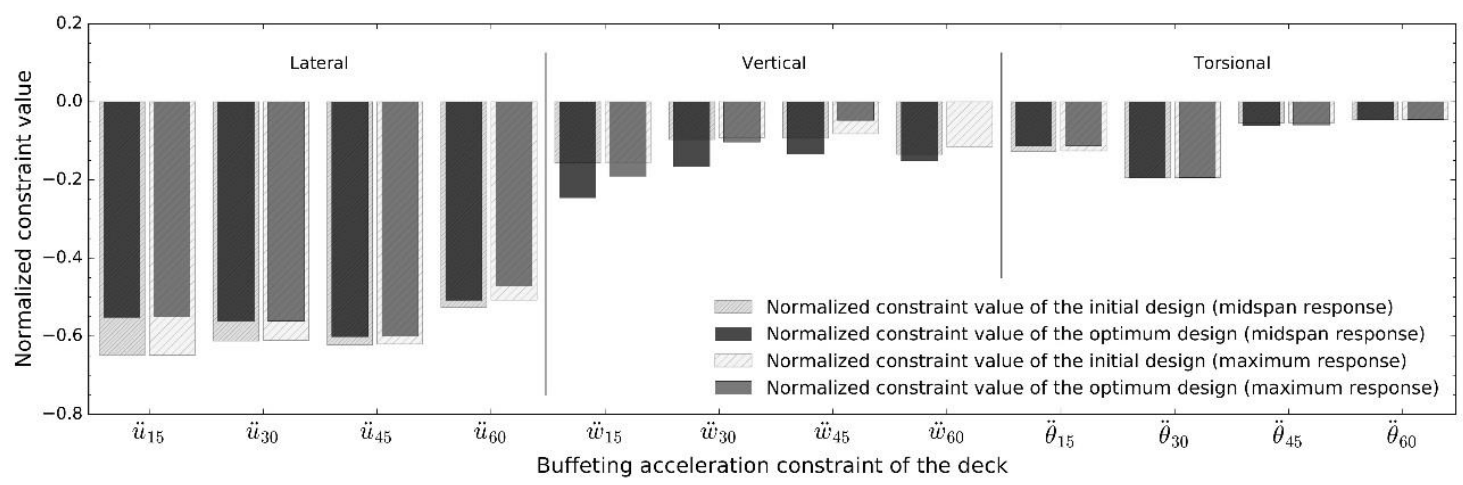

(a) Normalized constraints of RMS of accelerations of the deck in relevant deck response point.

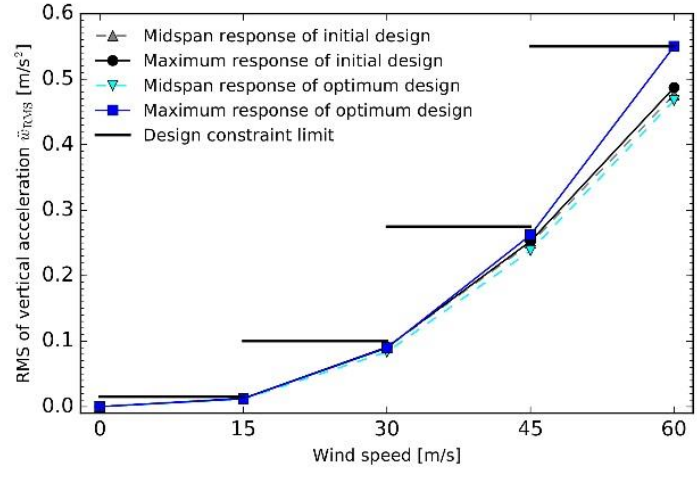

(b) Vertical buffeting response versus wind speed.

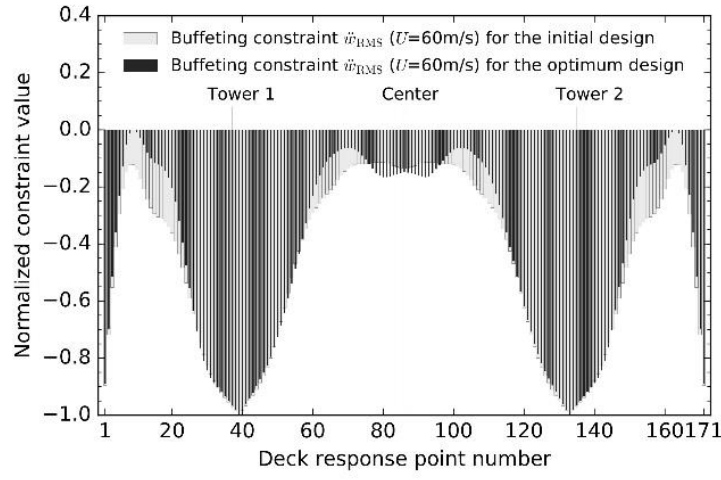

(c) Vertical buffeting constraint along the deck.

Figure 7: Subset of results: Buffeting constraints.

The cross-section geometry of the initial design of the deck is shown in Figure 5, along with the geometrical variations enabled in the optimization process. Shape modifications are controlled by the deck shape variables: the depth $H$ and the width $B$. The initial design $\left(B_{0}=40 \mathrm{~m}\right.$ and $\left.H_{0}=5.6 \mathrm{~m}\right)$ is similar to the deck geometry used in the main span of the Great Belt Bridge, while the range of variations considered $(8 \mathrm{~m}$ in the width, and $1.12 \mathrm{~m}$ in the depth) give place to changes in the fairing angle from $35.70^{\circ}$ to $92.63^{\circ}$ or in the width to depth ratio $B / H$ from 5.84 to 8.73. This enables the optimization algorithm to consider candidate designs similar to the crosssection of real bridges like the Tsing Ma Bridge, the Höga Kusten Bridge, or the Xiangshan Harbor Bridge, among many others. The initial design of the deck plate thickness is $t=25 \mathrm{~mm}$, the 
deck non-structural mass and mass moment of inertia are $M^{N S}=8 \mathrm{~T} / \mathrm{m}$ and $I^{N S}=2300 \mathrm{~T} * \mathrm{~m} / \mathrm{m}$, respectively. Subsequently, the natural frequencies of the first lateral, vertical and torsional modes are $0.082 \mathrm{~Hz}, 0.203 \mathrm{~Hz}$ and $0.461 \mathrm{~Hz}$, respectively, which are in the range of values of similar cable-stayed bridges.

Table 3. Mean value, coefficient of variation and distribution of the RV.

\begin{tabular}{llrcc}
\hline Random nature & Random variable & Mean $^{*}$ & $\mathrm{CoV}$ & Distribution \\
\hline Aerodynamics & $C_{D}[-]$ & $0.058^{\mathrm{s}}$ & 0.1 & Lognormal \\
& $C_{L}[-]$ & $-0.031^{\mathrm{s}}$ & 0.1 & Normal \\
& $C_{M}[-]$ & $0.035^{\mathrm{s}}$ & 0.1 & Normal \\
& $C_{D}^{\prime}[-]$ & $0.001^{\mathrm{s}}$ & Calculated $^{+}$ & Normal \\
& $C_{L}^{\prime}[-]$ & $5.452^{\mathrm{s}}$ & Calculated $^{+}$ & Normal \\
& $C_{M}^{\prime}[-]$ & $1.360^{\mathrm{s}}$ & Calculated $^{+}$ & Normal \\
\hline \multirow{2}{*}{ Wind } & $I_{u}[-]$ & 0.100 & 0.1 & Lognormal \\
& $I_{w}[-]$ & 0.050 & 0.1 & Lognormal \\
& $L_{u}[\mathrm{~m}]$ & 200.000 & 0.1 & Lognormal \\
& $L_{w}[\mathrm{~m}]$ & 20.000 & 0.1 & Lognormal \\
\hline Structural & $\xi[-]$ & 0.010 & 0.4 & Lognormal \\
\hline
\end{tabular}

Load cases: gravitational and buffeting loads: The gravitational load cases are the self weight $(S W)$ of the structure, and four live load cases $\left(L_{i}\right)$ that simulate the traffic loads. These live loads consist of a uniform load of $136 \mathrm{kN} / \mathrm{m}$ along the whole bridge in the first case $\left(L_{l}\right)$, and along the left, main, and right spans in the other cases: $L_{2}, L_{3}$ and $L_{4}$, respectively. The wind induced responses considered in this work are the RMS of accelerations in the lateral, vertical and torsional degrees-of-freedom (DoF) in 171 control points distributed along the deck, produced by buffeting at wind speeds $U=[15,30,45,60] \mathrm{m} / \mathrm{s}$. The wind is considered to have an air density of $\rho=1.22 \mathrm{Kg} / \mathrm{m}^{3}$, the turbulent intensities are set to $I_{u}=0.1$, and $I_{w}=0.05$, the turbulence integral length scales are $L_{u}=200 \mathrm{~m}$, and $L_{w}=20 \mathrm{~m}$, and the Von Karmam Spectrum is adopted. The space coherence is modeled using Davenport's formula (Davenport, 1967). The buffeting response are calculated in the frequency domain using an in-house software validated in the activities of the IABSE Task Group 3.1. (Diana et al. 2019a, 2019b).

Design constraints: The list of design constraints considered in this application case is provided in Table 1, and correspond to Eq. (7) and (8). The set of constraints includes 1104 structural constraints, including the displacements of deck and towers and stress levels of stays and deck under SW and live loads $L_{i}$, and 2052 buffeting constraints that set limitations to the accelerations on the deck. All these constraints are evaluated simultaneously for each candidate design proposed by the optimization algorithm, as depicted in Figure 1. It must be noted that the rotations of the deck in the buffeting responses are expressed in terms of the equivalent displacement $Z_{e q}=\theta * B / 2$, where $\theta$ is the deck rotation in radians.

Results and discussion: The results obtained by the deterministic aerostructural shape and size optimization are provided in Table 2 and Figures 6 and 7. Figures 6 (a) and (b), along with Table 2, provide the values of the optimum design. It can be appreciated that the depth of the deck cross-section has been modified to reach the upper bound value, since this contributes to increase the vertical stiffness, which improves the structural responses, and also to increase the torsional stiffness without worsen the aerodynamic performance (see Figure 2). The material of the stay supporting system has been redistributed, as shown in Figure 6 (b), where it is shown that the cross-section area of the stays in the center of the main span has grown, while in other 
stays where this material is not needed the cross-section area was reduced. Figures 6 (c) and 6 (d) show the constraints related to the stays for load case $L_{2}$ and the stress on the deck bottom fiber for load case $L_{0}$, respectively. In can be appreciated in Figures 6 (d) that the initial design of the bridge violated these constraints in some points along the deck next to the towers, but the optimization algorithm was able to modify the design to meet these stress requirements. This highlights its capability of reducing the material of the structure while improving the safety of the design. Figure 6 (e) and (f) show the convergence of the objective function and some relevant DV and constraints. In Figure 6 (f), the dependence of the buffeting response with the width of the deck cross-section is clearly shown. Figure 7 summarizes the buffeting design constraints for the three DoF. It must be mentioned that the maximum vertical acceleration, which is the active aeroelastic design constraint, is found in the lateral span, which emphasizes the need of considering a large number of control points along the bridge.

\section{APPLICATION CASE \#2: UNCERTAINTY QUANTIFICATION OF THE BUFFETING RESPONSE: IDENTIFICATION OF RELEVANT RV AND IMPLEMENTATION IN THE OPTIMIZATION PROCESS}

This second application case focuses on studying the influence of uncertainty in the buffeting responses of the bridge, aiming to ascertain their impact on the design. First, the most influential RV are identified by taking advantage of GSA. Later, the propagation of uncertainty in the buffeting response is studied. Finally, the possible implementation of the approaches under study into the aerostructural shape optimization methodology is discussed.

This application example is a further development of the previous one, since the deck crosssection, the aerodynamic surrogate model, wind modelling and most of the initial design values are the same. However, in this case, the structural system is a 3-DoF system with the natural frequencies of the first lateral, vertical and torsional modes of the full cable-stayed bridge analyzed in the previous example. Consequently, the buffetings responses are also different. The values obtained as deterministic buffeting responses at wind velocity $U=30 \mathrm{~m} / \mathrm{s}^{2}$ for the baseline design are: $\ddot{u}_{R M S}=0.0261 \mathrm{~m} / \mathrm{s}^{2}, \ddot{w}_{R M S}=0.2287 \mathrm{~m} / \mathrm{s}^{2}$ and $\ddot{\theta}_{R M S}=0.2394 \mathrm{~m} / \mathrm{s}^{2}$. It must be noted that the rotation response is expressed in terms of the equivalent vertical response of the deck as $Z_{e q}=\theta B / 2$. This example extends the previous one by introducing a number of RV in the problem, given that buffeting responses are influenced by uncertainties coming from different sources (see, for instance, Davenport, 1983, or Kareem, 1988a and 1988b). These are: (i) the wind characterization (wind velocity, air density, coherence parameters, turbulent intensities and length scales...); (ii) structural characterization (Young's modulus, structural damping...); and (iii) aerodynamic and aeroelastic characterization of the deck cross-section geometry (pressure distributions, force coefficients and slopes, flutter derivatives, admittance functions...). In this work, RV from the three groups are considered, which are summarized in Table 3.

One of the peculiarities of considering RV related with the shape of the deck cross section in frameworks where deck shape DV are also involved is that those properties are dependent on both the randomness and the DV. This is the case of the force coefficients and slopes, whose mean value is given by the ASM (Figure 2) depending on the value of the deck shape DV, and the probabilistic distribution of the RV (Table 3). Figure 8 shows the probabilistic distribution of the force coefficients and their slopes of the baseline design (in black), and the maximum and minimum values that those variables can take (in grey) based on the information provided by the ASM. The deterministic range of those responses is indicated as $D$ in this figure. 

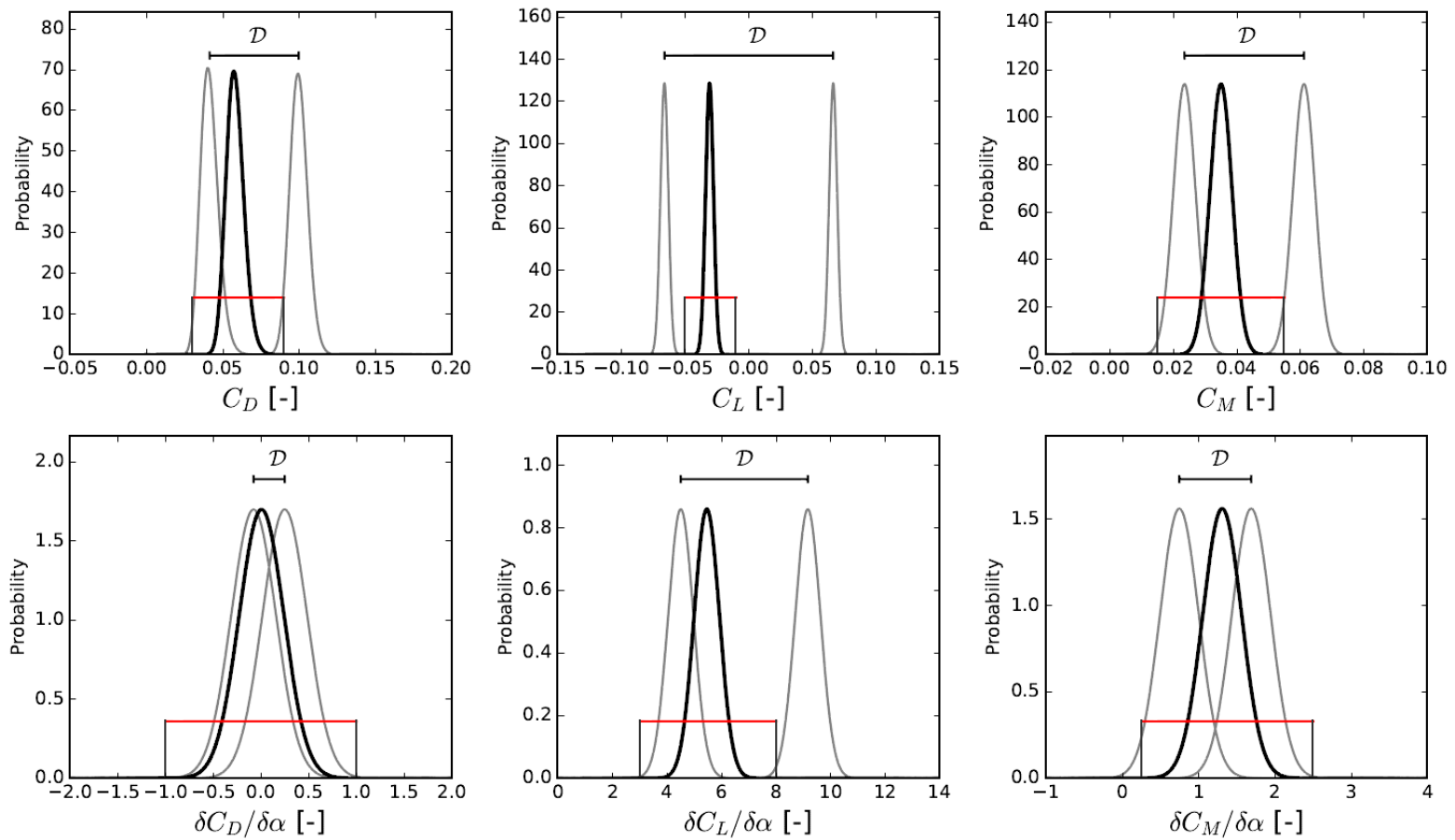

Figure 8: Probabilistic distributions of the force coefficients and slopes.

Aiming to ascertain the influence of each RV (see Table 3) in the buffeting response, a surrogate model was built with all the RV as inputs, the three DoF of the buffeting response as outputs, and considering the baseline deck geometry without shape variables $\left(H=H_{0} ; B=B_{0}\right)$. The distributions of the force coefficients and slopes adopted in the sampling plan were those indicated in red in Figure 8, while the other RV are modeled as described in Table 3. The resulting surrogate model was used to carry out GSA aiming to obtain the Sobol's indices for each RV and each buffeting response, as shown in Figure 9.
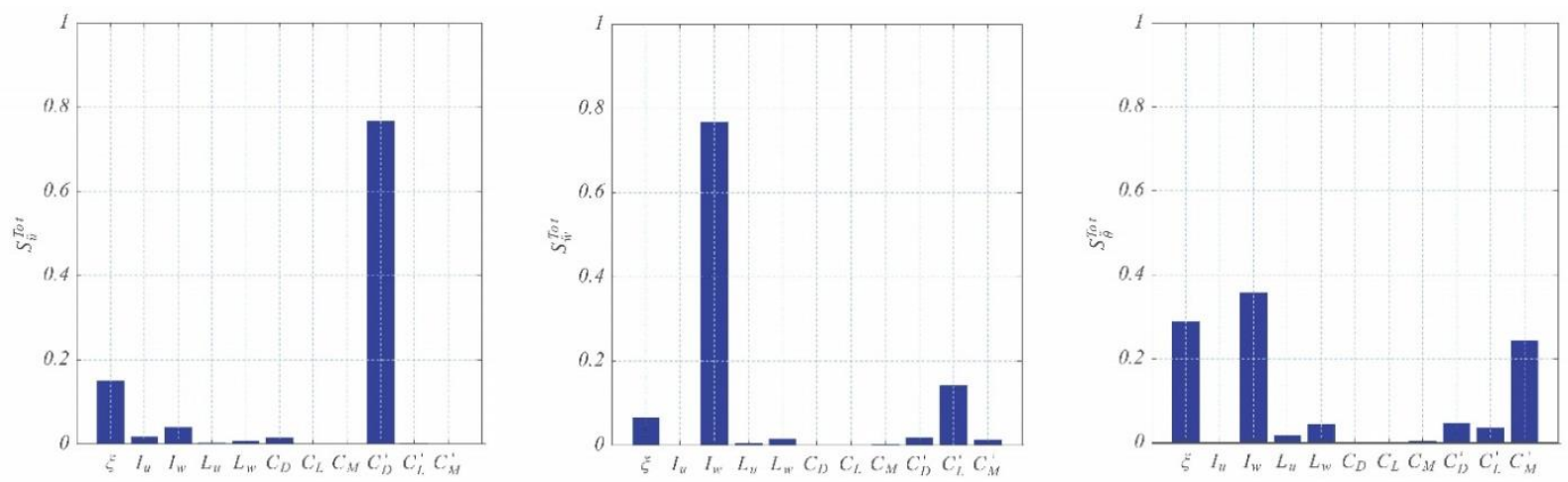

Figure 9: Uncertainty propagation for the three buffeting responses under study.

The resulting Sobol' indices clearly demonstrates that the application of dimensionality reduction is pertinent in this problem, and therefore it must be considered in any design framework including uncertainty. Particularly, the influence of the force coefficients $\left(C_{D}, C_{L}\right.$, $\left.C_{M}\right)$, and the horizontal components of the turbulence $\left(I_{u}\right)$ and length scale $\left(L_{u}\right)$ on the buffeting responses is almost negligible. This enables to define a set of relevant RV including the structural damping $(\xi)$, the vertical components of both turbulence intensity $\left(I_{w}\right)$ and length scale 
$\left(L_{w}\right)$, and the slopes of the force coefficients $\left(C^{\prime}{ }_{D}, C^{\prime}{ }_{L}, C^{\prime} M\right)$. These are the RV that must be considered in design frameworks including uncertainty for this particular problem, as the one described in Figure 3 for the reliability-based tailoring of bridge decks.

Figure 10 shows the results of the uncertainty propagation in the buffeting response for the baseline deck design by using Monte Carlo sampling and the aforementioned surrogate model of the buffeting response. It can be appreciated that the lateral acceleration is clearly a lognormal distribution, the vertical response is also lognormal, while the torsional response is more similar to a normal distribution. It must be also noted that all responses present a relevant dispersion, particularly the torsional response. This emphasizes the necessity of including the effects of uncertainty in the buffeting response in the design process.
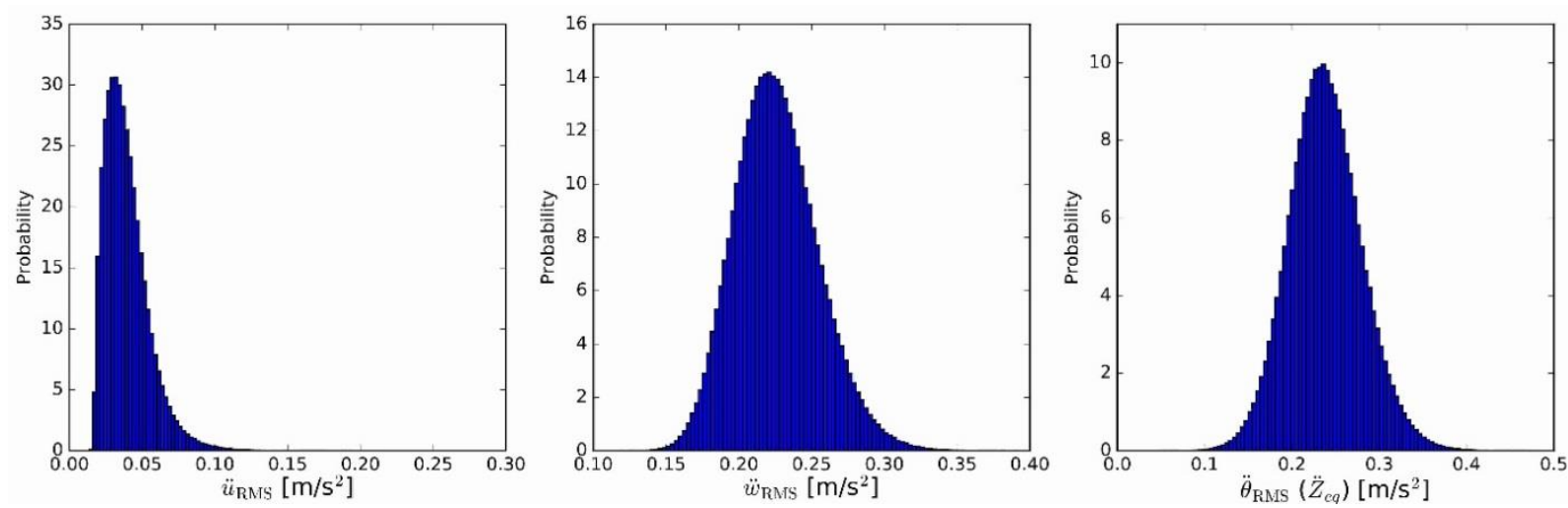

Figure 10: Uncertainty propagation for the three buffeting responses under study.

Hence, the following step in this research line is the reformulation of the optimization problem into an aerostructural reliability-based design optimization (BRDO) problem, taking advantage of the design frameworks described in Figure 1 and 3. It must be remarked that using the first step of the RBT process described in Figure 3 before the optimization process would reduce the computational demands. Its application to simple structures such as 3-DoF systems is straightforward, but more research is required to be efficiently applied in full bridge models considering a large number of design variables, as it was the case of the first application example presented in this work, or in the author's previous work Cid Montoya 2018b.

\section{CONCLUSIONS AND FUTURE WORK}

This paper describes the most recent advances in the development of numerical design frameworks for the aerostructural shape optimization of long-span bridges conducted by the authors. The methodology for the aerostructural optimization is presented and an application example consisting of a long-span cable-stayed bridge under the action of turbulent wind is optimized. This was achieved by modifying the deck shape and deck plate thickness and redistributing the material of the cable supporting-system by defining a more efficient distribution of stay cross-section areas. The resulting design reduces the total required material by more than $8 \%$ while meeting all the structural and buffeting design constraints.

This work also discusses the effects of uncertainty in the aerostructural design of long-span bridges by analyzing the uncertainty propagation in the buffeting response of a 3DoF system with the same deck cross-section. The impact of each random variable in the buffeting response was analyzed using global sensitive analyses. It was found that the damping, the vertical components of the turbulence intensity and length scale, and the slopes of the force coefficients 
are the most influential random variables in this problem. The uncertainty quantification analyses show that the distribution of the buffeting responses present a noticeable dispersion. This remarks the need for considering uncertainty in the wind-resistant design and optimization of long-span bridges.

In forthcoming contributions, an efficient framework for the aerostructural reliability-based design optimization will be developed.

\section{ACKNOWLEDGEMENTS}

This research has been funded by the Spanish Ministry of Economy and Competitiveness in the frame of the research project with reference BIA2016-76656-R, and the Galician regional government, including FEDER funding, with reference ED431C 2017/72. M. Cid Montoya is funded by the Galician regional government with reference ED481B 2018/053 and the Fulbright postdoctoral scholarship program. A. Kareem especially thanks NSF support under grant CMMI \#1612843. Fei Ding is supported by a grant from the Center for Informatics and Computational Sciences.

\section{REFERENCES}

Argentini T, Pagani A, Rocchi D, Zasso A. (2014) Monte Carlo analysis of total damping and flutter speed of a long span bridge: Effects of structural and aerodynamic uncertainties. $J$. of Wind Eng. and Ind. Aero., 128: 90-104.

Bernardini E., Spence S.M.J., Wei D. and Kareem A. (2015) Aerodynamic shape optimization of civil structures: a Kriging-assisted CFD-based approach. J of Wind Engineering and Ind. Aero., 144: 154-164.

Caracoglia L. (2008) Influence of uncertainty in selected aerodynamic and structural parameters on the buffeting response of long-span bridges. J. Wind Eng. Ind. Aerodyn. 96 327-344

Cid Montoya, M., Nieto, F., Hernández, S., Kusano, I., Álvarez, A. J. and Jurado, J. Á. (2018a) "CFD-based aeroelastic characterization of streamlined bridge deck cross-sections subject to shape modifications using surrogate models." Journal of Wind Engineering and Industrial Aerodynamics, 177:405-428.

Cid Montoya, M., Hernández, S., and Nieto, F. (2018b) "Shape optimization of streamlined decks of cable-stayed bridges considering aeroelastic and structural constraints." Journal of Wind Engineering and Industrial Aerodynamics, 177:429-455.

Cid Montoya, M., Nieto, F., Hernández, S., and Jurado, J. Á. (2019a) “On the aerostructural design of long-span cable-stayed bridges: The contribution of parameter variation studies with focus on the deck design." Lecture Notes in Civil Engineering, vol 27, 234-246.

Cid Montoya, M., Hernández, S., Nieto, F., Kareem, A., and Jurado, J. Á. (2019b)

"Aerostructural shape and size optimization of a long-span cable-stayed bridge considering service loads, static wind loads, torsional divergence, flutter and buffeting constraints." The 15th International Conference on Wind Engineering, Beijing, China, September 1-6, 2019.

Cid Montoya, M., Ding, F., Kareem, A., Hernández, S., Nieto, F., Baldomir, A. (2019c). “A reliability based tailoring of bridge deck shape for buffeting response." The 15th International Conference on Wind Engineering, Beijing, China, September 1-6, 2019.

Davenport, A. G. (1967b). The dependence of wind loads on meteorological parameters. International research seminar: Wind Effects on Buildings and Structures.

Davenport A. G. (1983) The relationship of reliability to wind loading. J. Wind Eng. Ind. Aerodyn. 13: 3-27. 
Diana G, Stoyanoff S, Aas-Jakobsen k, Allsop A, Andersen M, Argentini A, Cid Montoya M, Hernández S, Jurado JA, Katsuchi H, Kavrakov I, Kim H-K, Larose G, Larsen A, Morgenthal G, Oiseth O, Omarini S, Rocchi D, Svendsen M and Wu T (2019). IABSE Task Group 3.1 benchmark results. Part 1: Numerical analysis of a 2-degree-of-freedom bridge deck section based on analytical aerodynamics. Structural Engineering International (IABSE), DOI: 10.1080/10168664.2019.1639480.

Diana G, Stoyanoff S, Aas-Jakobsen k, Allsop A, Andersen M, Argentini A, Cid Montoya M, Hernández S, Jurado JA, Katsuchi H, Kavrakov I, Kim H-K, Larose G, Larsen A, Morgenthal G, Oiseth O, Omarini S, Rocchi D, Svendsen M and Wu T (2019). IABSE Task Group 3.1 benchmark results. Part 2: Numerical analysis of a 3-degree-of-freedom bridge deck section based on experimental aerodynamics. Structural Engineering International (IABSE), DOI: 10.1080/10168664.2019.1661331.

Ding, F., Kareem, A. (2018) A multi-fidelity shape optimization via surrogate modeling for civil structures. Journal of Wind Engineering and Industrial Aerodynamics, 178: 49-56.

Elshaer, A., Bitsuamlak, G., El Damatty, A. (2017) Enhancing wind performancing of tall buildings using corner aerodynamic optimization. Engineering Structures, 136: 133-148.

Ferreira, F. L. S., Simões L. M. C. (2011) Optimum design of a controlled cable stayed bridge subject to earthquakes. Structural and Multidisciplinary Optimization, 44(4) 517-528.

Forrester AIJ, Sobester A, Keane AJ. (2008) Engineering design via surrogate modeling. Wiley.

Ge, Y.J., Xian, H.F., Tanaka, H. (2000) Application of a reliability analysis model to bridge flutter under extreme winds. J. Wind Eng. Ind. Aerodyn. 86(2-3) 155-167.

Kareem A. (1988a) Effect of parametric uncertainties on wind excited structural response. $J$. Wind Eng. Ind. Aerodyn. 30 233-241.

Kareem A. (1988b) Aerodynamic response of structures with parametric uncertainties. Struc. Safety, 5 205-225.

Kusano I., Baldomir A., Jurado J. A., and Hernández S. (2014) Reliability based design optimization of long-span bridges considering flutter. Journal of Wind Engineering and Industrial Aerodynamics, 135:149-162.

Kusano I., Baldomir A., Jurado J. A., and Hernández S. (2018) The importance of correlation among flutter derivatives for the reliability based optimum design of suspension bridges. Engineering Structures, 173:416-428.

Larose, G. L. and Livesey, F. M. (1997) "Performance of streamlined bridge decks in relation to the aerodynamics of a flat plate." Journal of Wind Engineering and Industrial Aerodynamics, 69-71:851-860.

Mannini C, Bartoli G. (2015) Aerodynamic uncertainty propagation in bridge flutter analysis. Struc. Safety. 52 29-39.

Menter F, Esch T. (2001) Elements of industrial heat transfer prediction. $6^{\text {th }}$ Brazilian Congress of Mechanical Eng 2001.

Nieto, F. Hernández, S., Jurado, J.A. (2009) Optimum design of long-span suspension bridges considering aeroelastic and kinematic constraints. Structural and Multidisciplinary Optimization 39 133-151.

Scanlan RH \& Tomko JJ (1971) Airfoil and bridge deck flutter derivatives. J of Eng Mech Div, 97(6): 1717-1737.

Simões LMC and Negrão JHO, (1994) Sizing and geometry optimization of cable-stayed bridges. Computers \& Structures, 52(2) 309-321.

Sobol' IM. (2001) Global sensitivity indices for nonlinear mathematical models and their Monte 
Carlo estimates. Mathematics and Computers in Simulation 55, 271-280,

Solari G. and Piccardo G. Probabilistic (2001) 3-D turbulence modeling for gust buffeting of structures. Probabilistic Engineering Mechanics 16: 73-86.

Tubino F. (2005) Relationship among aerodynamic admittance functions, flutter derivatives and static coefficients for long-span bridges. J Wind Eng. Ind. Aerodyn. 93: 929-950. 